\title{
BMJ Open Pre-existing hyperlipidaemia increased the risk of new-onset anxiety disorders after traumatic brain injury: a 14-year population-based study
}

\author{
Chung-Han Ho, ${ }^{1,2}$ Kuang-Yang Hsieh, ${ }^{3,4}$ Fu-Wen Liang, ${ }^{5}$ Chia-Jung Li, ${ }^{6}$ \\ Jhi-Joung Wang, ${ }^{1}$ Chung-Ching Chio, ${ }^{1,7}$ Chin-Hung Chang, ${ }^{1}$ Jinn-Rung Kuo ${ }^{1,4,7}$
}

To cite: Ho C-H, Hsieh K-Y, Liang F-W, et al. Pre-existing hyperlipidaemia increased the risk of new-onset anxiety disorders after traumatic brain injury: a 14-year population-based study. BMJ Open 2014;4:e005269. doi:10.1136/bmjopen-2014005269

- Prepublication history for this paper is available online. To view these files please visit the journal online (http://dx.doi.org/10.1136/ bmjopen-2014-005269).

Received 16 March 2014 Revised 16 June 2014 Accepted 23 June 2014

CrossMark

For numbered affiliations see end of article.

Correspondence to Dr Jinn-Rung Kuo; kuojinnrung@gmail.com

\section{ABSTRACT}

Objectives: Anxiety disorders (ADs) are common after traumatic brain injury (TBI). However, the risk factors of new-onset ADs remain unclear. This study was aimed at evaluating the incidence and risk factors for new-onset ADs, including pre-existing hyperlipidaemia and three major comorbidities (diabetes mellitus, hypertension and cardiovascular disease), in patients with TBI.

Setting: A matched cohort study was conducted using the Taiwan Longitudinal Health Insurance Database between January 1997 and December 2010.

Participants: A total of 3822 participants (1274 patients with TBI with hyperlipidaemia and 2548 agematched and gender-matched patients with TBI without hyperlipidaemia).

Outcome measures: The incidence and HRs for the development of new-onset ADs after TBI were compared between the two groups.

Results: The overall incidence rate of new-onset ADs for patients with TBI with hyperlipidaemia is 142.03/ 10000 person-years (PYs). Patients with TBI with hyperlipidaemia have a 1.60 -fold incidence rate ratio $(p<0.0001)$ and increased HR of ADs $(1.58,95 \% \mathrm{Cl}$ 1.24 to 2.02) compared with those without hyperlipidaemia. The incidence rates of ADs for males and females with hyperlipidaemia, respectively, were 142.12 and 292.32/10 000 PYs, which were higher than those without hyperlipidaemia (93.03 and 171.68/ 10000 PYs, respectively). Stratified by age group, hyperlipidaemia is a risk factor of ADs for patients with TBI aged 65 years or younger.

Conclusions: Pre-existing hyperlipidaemia is an independent predictor of new-onset ADs in patients with $\mathrm{TBI}$, even when controlling for other demographic and clinical variables. Female patients with pre-existing hyperlipidaemia had significantly higher risk of newonset ADs than males, especially between the ages of 35 and 65 years.

\section{INTRODUCTION}

Traumatic brain injury (TBI) has a high incidence rate and is a major cause of death and

\section{Strengths and limitations of this study}

- To the best of our knowledge, there are no published studies investigating the risk of new-onset anxiety in traumatic brain injury (TBI) patients with hyperlipidaemia based on the population database.

- The information that hyperlipidaemia is an independent risk factor of new-onset anxiety after TBI may play a role in preventive medicine.

- In the claims data, disease was recorded using International Classifications of Disease-9 which may be misclassified.

- As a retrospective observational study, our results could be biased by unrecognised confounders which may influence the development of anxiety after TBI.

disability in humans. From the global estimation, 57 million people may have been hospitalised with TBIs and about 1.5 million die. ${ }^{1}$ The annual incidence of TBI is $\sim 1.7$ million in the USA. ${ }^{2}$ The yearly incidence of TBI is estimated at 235/100000 people in the European Union, ${ }^{3}$ and about 160-344/ 100000 people in Asia. ${ }^{4}$

However, the assessment and treatment of TBI typically focus on physical and cognitive impairments, even though neuropsychiatric impairments represent significant causes of disability. ${ }^{6}$ TBI can result in various neuropsychiatric disorders, including cognitive impairments, depression or anxiety disorders (ADs) and behavioural problems. These post-TBI neuropsychiatric impairments contribute to disability after TBI, which becomes a chronic problem for an estimated 3.17 million in the USA. ${ }^{7}$ Therefore, evaluating the risk factors associated with the new-onset psychiatric problem after TBI is an important issue in the field of neuropsychiatry.

The risk of developing neuropsychiatric disorders after TBI ranges from $21 \%$ to 
$65 \% .^{8-10}$ Patients with TBI with psychiatric disorders were associated with significantly greater costs (approximately 3.39 times) than patients with TBI without psychiatric disorders; hence, TBI represents a major public health issue. ${ }^{11}$ ADs, one of the common psychiatric disorders, is defined as worrying about the future state of arousal with the feeling of a non-specific threat ${ }^{12}$; the prevalence of ADs is $11-70 \%$ in patients with TBI. ${ }^{9} 13-15$ However, the risk factors of new-onset ADs after TBI remain unclear.

Besides TBI insults, age, ${ }^{16}$ sex,${ }^{17}$ cardiovascular disease (CAD) ${ }^{18}{ }^{19}$ hypertension (HTN),${ }^{20}{ }^{21}$ diabetes mellitus $(\mathrm{DM})^{20}{ }^{22}$ and hyperlipidaemia are risk factors associated with ADs. ${ }^{23} 24$ Among these $\mathrm{AD}$ risk factors, hyperlipidaemia was also related to the risk of CAD, $\mathrm{DM}^{20}$ and HTN. ${ }^{25}$ It has been reported that taking antihyperlipidaemia drugs, such as Statin, could restore anxiety-like deficits after TBI in an animal model. ${ }^{26}$ Furthermore, hyperlipidaemia has been considered associated with depression in general condition. ${ }^{27}$ However, to the best of our knowledge, few studies have examined the association between hyperlipidaemia and the risk of new-onset ADs in patients with TBI.

So far, the incidence and risk factors of new-onset AD symptoms in patients with TBI with hyperlipidaemia remain unclear. Therefore, the aim of this study was to evaluate the risk factors for developing $\mathrm{ADs}$ in patients with TBI with or without previous hyperlipidaemia using data from the nationwide database of the National Health Insurance (NHI) Programme in Taiwan (19972010). We attempted to clarify the long-term effects of pre-existing hyperlipidaemia on new-onset ADs among patients with TBI. We propose that awareness of the incidence and risk factors for new-onset $\mathrm{ADs}$ in patients with TBI can improve not only one's understanding of the sequelae of brain injury but also patient treatment and the rehabilitation protocol.

\section{METHODS}

Data sources and researches

In this study, data were obtained from the National Health Insurance Research Database (NHIRD) in Taiwan between January 1997 and December 2010. The NHIRD covers $99 \%$ of inpatient and outpatient medical benefit claims for Taiwan's 23 million residents. The database comprises detailed information regarding clinical visits for each insured participant, including diagnostic codes according to the clinical modification of the International Classifications of Disease-9 (ICD-9-CM) and prescription details. ${ }^{28} 29$ For a population-base medical research purpose, the NHIRD has released a database of medical claims of 1000000 random participants, approximately $4.3 \%$ of the population in various studies. All datasets can be interlinked through each individual's unique personal identification number. The Institutional Review Board of Chi-Mei Medical Center approved this study for exemption.
Study details

We accessed the diagnostic codes through the inpatient and outpatient claims databases of the NHI. Participants were selected from the partial sample of the one million individuals. The study protocol was as follows: patients with a diagnosis of TBI (ICD-9-CM code: 801-804 and 850-854) between 1997 and 2010 were selected. Pre-existing hyperlipidaemia was defined as three times of outpatient visits or one inpatient admission due to hyperlipidaemia (ICD-9-CM code: 272.0, 272.1, 272.2, 272.4) before the TBI diagnosis. Since hyperlipidaemia was often in men aged older than 35 and women older than $55,{ }^{30}$ a 1:2 age-gender and gender-matched cohort without pre-existing hyperlipidaemia was selected for avoiding potential confounders.

To avoid potential confounders, a 1:2 age-gender and gender-matched cohort without pre-existing hyperlipidaemia was selected. The event of ADs was defined as three times of outpatient visits or one inpatient admission with an $\mathrm{AD}$ diagnosis (ICD-9-CM code: 300.xx were included but 300.4:dysthymic disorder was excluded) between the date of TBI diagnosis and 31 December 2010. Patients with a psychiatric disorder such as schizophrenic disorders (ICD-9-CM codes: 295); episodic mood disorders (ICD-9-CM codes: 296); delusional disorders (ICD-9-CM codes: 297); anxiety, dissociative and somatoform disorders (ICD-9-CM codes: 300) and personality disorders (ICD-9-CM codes: 301) before TBI were excluded. This method of selection has been used extensively in various published studies using the Taiwan NHIRD. ${ }^{31-33}$ The baseline comorbidities prior to TBI, including HTN (ICD-9-CM code: 401-405, 437.2 and 362.11), DM (ICD-9-CM code: 250, 357.2, 362.0 and 366.41) and CAD (ICD-9-CM code: 410-414), were determined, as these diagnoses are important factors affecting episodes of mental disorders.

To estimate the risk of ADs, demographic and clinical information, including age, sex, hyperlipidaemia, DM, HTN and CAD, were obtained directly from each subject's file in the NHI insurance database. Age was classified into four categories: \35, 35-50, 50-65 and $\geq 65$ years old.

\section{Statistical analysis}

Pearson's $\chi^{2}$ test was used to analyse distribution differences in age group, gender, AD, HTN, DM and CAD between patients with TBI with and without hyperlipidaemia. Student t test and the Wilcoxon rank-sum test were used to compare age at first TBI diagnosis and time to ADs, respectively.

The incidence rate of ADs was calculated from the number of patients with TBI with ADs divided by the total person-years as rates per $10000 \mathrm{PYs}$ of observation. The Poisson regression was applied to calculate the incidence rate ratios of $\mathrm{ADs}$ with $95 \%$ CIs between patients with TBI with/without hyperlipidaemia. In addition, the Kaplan-Meier failure plot was applied to describe the cumulative incidence rate of ADs; the log-rank test was 
used to compare the risk difference between two groups. The relative risks adjusted for potential confounding variables were estimated by the Cox regression. In the survival analysis, the subjects who died were considered censored, and the censoring date was their date of mortality. The statistical software, Statistical Analysis System (SAS) (V.9.3; SAS Institute, Inc, Cary, North Carolina, USA), was used to perform all statistical analyses. Kaplan-Meier curves were generated using STATA (V.12; Stata Corp., College Station, Texas, USA). All significance levels were set at $\mathrm{p}$ value $<0.05$.

\section{RESULTS}

Table 1 shows the distribution of demographical variables between patients with TBI with and without hyperlipidaemia. A total of 3822 adult patients were enrolled in this study. After matching by age and gender, group differences in comorbidity of HTN, DM and CAD were determined. Patients with TBI with hyperlipidaemia $(10.75 \%)$ had significantly more ADs than patients with TBI without hyperlipidaemia (6.95\%). Patients with TBI with hyperlipidaemia developed new-onset ADs (median: 2.40 years, IQR: 0.93-4.42) earlier than patients with TBI without hyperlipidaemia (median: 2.70 years, IQR: 0.91-4.81). The overall follow-up median time is 5.44 years (IQR: 2.20-9.07).

Figure 1 shows the prevalence of ADs for patients with TBI with hyperlipidaemia increased from 7.85/10 000 in 1997 to $431.71 / 10000$ in 2010. The estimated prevalence of ADs among patients with TBI without hyperlipidaemia is consistently lower than those with hyperlipidaemia.

The overall incidence rate of new-onset ADs after TBIs is 142.03/10 000 PYs. Table 2 shows that patients with TBI with hyperlipidaemia have a 1.60 -fold incidence rate ratio of ADs compared with patients with TBI without hyperlipidaemia. The patients with TBI aged 35-65 years had a significant difference in the ADs incidence ratio between patients with/without hyperlipidaemia. In addition, female patients with TBI with hyperlipidaemia had a higher incidence rate (292.32/10 000 PYs) than males (142.12/10 000 PYs). There was no significant difference in the incidence rate of ADs in patients with comorbid HTN, DM or CAD compared with those without the aforementioned comorbidities. Patients with TBI with hyperlipidaemia have a 1.58 -fold (95\% CI 1.24 to 2.02) risk of ADs compared with patients with TBI without hyperlipidaemia, even when controlling for age, sex, HTN, DM and CAD. Females have a 1.84-fold (95\% CI 1.47 to 2.30) risk of ADs compared with male patients with TBI.

In addition, patients with TBI with hyperlipidaemia were more likely to experience ADs than those without hyperlipidaemia in any given month during the follow-up. The Kaplan-Meier plot (figure 2) indicated that patients with TBI with hyperlipidaemia developed ADs more quickly than those without hyperlipidaemia. The cumulative probability of ADs in hyperlipidaemia patients was $3.00 \%$ (95\% CI $2.17 \%$ to $4.14 \%$ ) at 1 year,

Table 1 Demographics and clinical characteristics of traumatic brain injury (TBI) patients with and without pre-existing hyperlipidaemia

\begin{tabular}{|c|c|c|c|}
\hline & TBIs with hyperlipidaemia $(\mathrm{N}=1274)$ & TBIs without hyperlipidaemia $(\mathrm{N}=2548)$ & p Value ${ }^{*}$ \\
\hline Age $($ mean $\pm S D)$ & $59.45 \pm 15.37$ & $59.45 \pm 15.37$ & 0.9991 \\
\hline \multicolumn{4}{|l|}{ Age group } \\
\hline$\leq 35$ & $82(6.44)$ & $164(6.44)$ & \multirow[t]{4}{*}{1.0000} \\
\hline $35-50$ & $274(21.51)$ & $548(21.51)$ & \\
\hline $50-65$ & 399 (31.32) & 797 (31.28) & \\
\hline$>65$ & $519(40.74)$ & $1039(40.78)$ & \\
\hline \multicolumn{4}{|l|}{ Gender } \\
\hline Male & $860(67.50)$ & $1720(67.50)$ & \multirow[t]{2}{*}{1.0000} \\
\hline Female & $414(32.50)$ & $828(32.50)$ & \\
\hline \multicolumn{4}{|l|}{ Hypertension } \\
\hline Yes & 557 (43.72) & $425(16.68)$ & \multirow[t]{2}{*}{$<0.0001$} \\
\hline No & $717(56.28)$ & 2123 (83.32) & \\
\hline \multicolumn{4}{|l|}{ Diabetes mellitus } \\
\hline Yes & $446(35.01)$ & $217(8.52)$ & \multirow[t]{2}{*}{$<0.0001$} \\
\hline No & $828(64.99)$ & 2331 (91.48) & \\
\hline \multicolumn{4}{|c|}{ Cardiovascular disease } \\
\hline Yes & 201 (15.78) & $135(5.30)$ & \multirow[t]{2}{*}{$<0.0001$} \\
\hline No & 1073 (84.22) & $2413(94.70)$ & \\
\hline \multicolumn{4}{|l|}{ Anxiety disorders } \\
\hline Yes & $137(10.75)$ & $177(6.95)$ & \multirow[t]{2}{*}{$<0.0001$} \\
\hline No & $1137(89.25)$ & $2371(93.05)$ & \\
\hline \multicolumn{4}{|c|}{ Time to anxiety disorders (years) } \\
\hline Median (IQR) & $2.40(0.93-4.42)$ & $2.70(0.91-4.81)$ & 0.3968 \\
\hline
\end{tabular}


Figure 1 Overall prevalence of new-onset anxiety disorders for traumatic brain injury patients with/without pre-existing hyperlipidaemia.

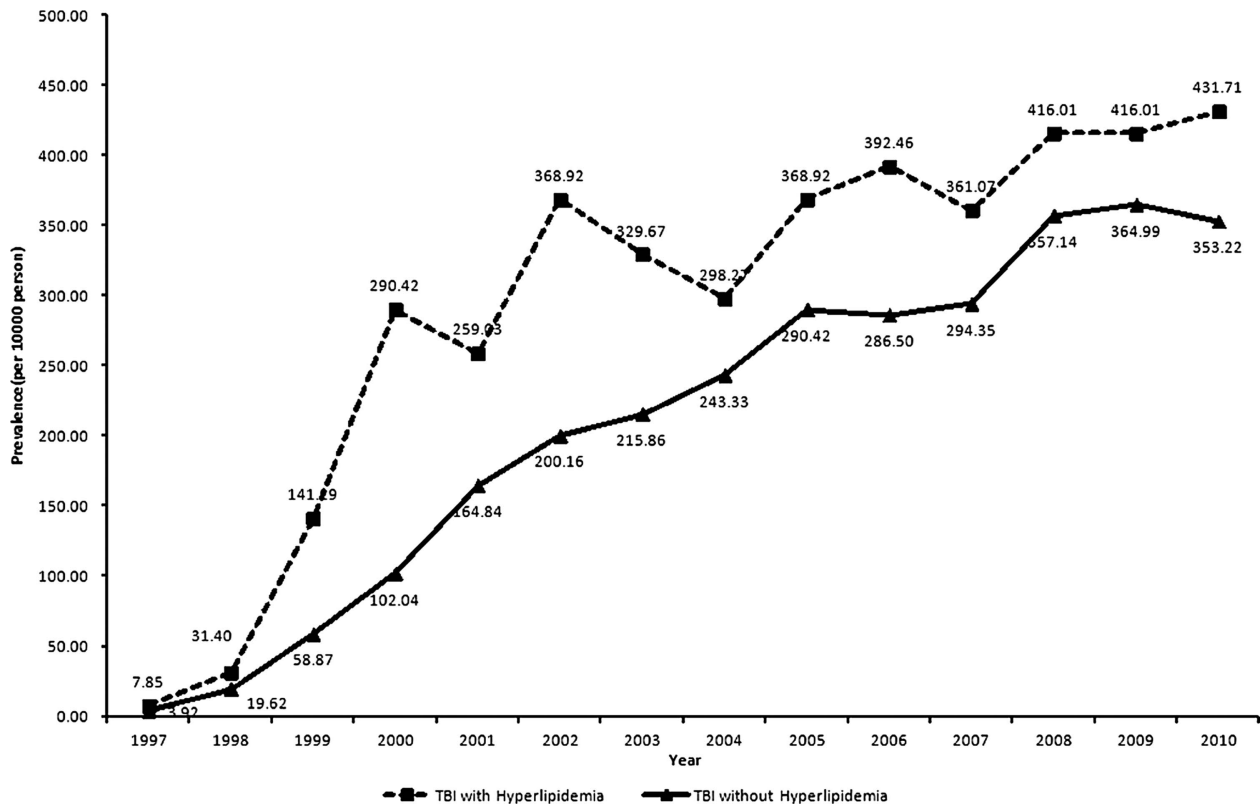

in females aged 35-65 years, is an independent risk factor for developing new-onset ADs after TBI. Because the NHIRD covers nearly $99 \%$ of inpatient and outpatient medical benefit claims for the 23 million residents in Taiwan, these results closely approximate the true distribution of ADs among patients with TBI with pre-existing hyperlipidaemia in Taiwan. This information is critical to alter the course of and prevent TBI-related disability.

Our findings were consistent with previous study that ADs are common in the general population and may be even more common in individuals with traumatic brain injuries. ${ }^{34}$ In our 14-year population-based study, we found that the prevalence of ADs in patients with TBI with hyperlipidaemia increased from 7.85/10 000 in 1997 to $431.71 / 10000$ in 2010. We also found the incidence of new-onset ADs in pre-existing hyperlipidaemia after TBI is $10.75 \%$ and $189.43 / 10000$ PYs, the overall cumulative ADs rate is $17.62 \%$, and approximately $43 \%$ of ADs cases occurred within 2 years after TBI, which were all significant when compared with patients with TBI without hyperlipidaemia $(\mathrm{p}<0.0001)$. The incidence rate of $\mathrm{ADs}$ supports the validity of the high prevalence rate of ADs among patients with TBI with pre-existing hyperlipidaemia. These results imply these individuals are at increased risk for $\mathrm{AD}$ after $\mathrm{TBI}$ and pre-existing hyperlipidaemia may play an important role in the development of new-onset ADs after TBI.

In Taiwan, the prevalence of hyperlipidaemia for adults ranged from $10.2 \%$ to $13.4 \% .^{33}$ The incidence rate of TBI was 344/100 000 people in Taiwan. ${ }^{5}$ To the best of our knowledge, this is the first study to show the prevalence of ADs for patients with TBI with pre-existing hyperlipidaemia. The fact that the prevalence of ADs for patients with TBI continually increased over 14 years highlights the possible characteristics of ADs for patients with TBI. Although, at the beginning of the NHI
To the best of our knowledge, this is the first study to demonstrate that pre-existing hyperlipidaemia, especially 
Table 2 Incidence of anxiety disorders in traumatic brain injury patients with and without pre-existing hyperlipidaemia

\begin{tabular}{|c|c|c|c|c|c|c|c|c|c|c|c|}
\hline & \multicolumn{4}{|c|}{ TBI with hyperlipidaemia } & \multicolumn{4}{|c|}{ TBI without hyperlipidaemia } & \multirow[b]{2}{*}{ IRR $^{\star}(95 \% \mathrm{Cl})$} & \multirow{2}{*}{$\begin{array}{c}\text { Crude HR } \\
(95 \% \mathrm{Cl})\end{array}$} & \multirow{2}{*}{$\begin{array}{l}\text { Adjusted† HR } \\
(95 \% \mathrm{Cl})\end{array}$} \\
\hline & $\overline{\mathbf{N}}$ & ADs & PY & IR & $\overline{\mathbf{N}}$ & ADs & PY & IR & & & \\
\hline Total & 1274 & 137 & 7217.41 & 189.82 & 2548 & 177 & 14890.15 & 118.87 & $1.60(1.28 \text { to } 2.00)^{\ddagger}$ & $1.58(1.27 \text { to } 1.98)^{\ddagger}$ & $1.58(1.24 \text { to } 2.02)^{\ddagger}$ \\
\hline$\leq 35$ & 82 & 7 & 651.46 & 107.45 & 164 & 8 & 1335.06 & 59.92 & 1.79 (0.65 to 4.94$)$ & 1.00 (ref.) & 1.00 (ref.) \\
\hline $35-50$ & 274 & 29 & 1779.58 & 162.96 & 548 & 36 & 3657.26 & 98.43 & $1.66(1.02 \text { to } 2.70)^{\$}$ & 1.47 (0.84 to 2.58$)$ & $1.33(0.75$ to 2.33$)$ \\
\hline $50-65$ & 399 & 53 & 2128.21 & 249.04 & 797 & 53 & 4471.10 & 118.54 & $2.10(1.44 \text { to } 3.07)^{\ddagger}$ & $1.87(1.09 \text { to } 3.21)^{\$}$ & $1.52(0.88$ to 2.64$)$ \\
\hline$>65$ & 519 & 48 & 2658.16 & 180.58 & 1039 & 80 & 5426.74 & 147.42 & $1.22(0.86$ to 1.75$)$ & $1.82(1.07 \text { to } 3.11)^{\$}$ & $1.43(0.82$ to 2.49$)$ \\
\hline \multicolumn{12}{|l|}{ Gender } \\
\hline Male & 860 & 70 & 4925.39 & 142.12 & 1720 & 93 & 9997.31 & 93.03 & $1.53(1.12 \text { to } 2.08)^{\$}$ & 1.00 (ref.) & 1.00 (ref.) \\
\hline Female & 414 & 67 & 2292.02 & 292.32 & 828 & 84 & 4892.85 & 171.68 & $1.70(1.24 \text { to } 2.35)^{\$}$ & $1.90(1.52 \text { to } 2.37)^{\ddagger}$ & $1.84(1.47 \text { to } 2.30)^{\ddagger}$ \\
\hline \multicolumn{12}{|c|}{ Hypertension } \\
\hline No & 717 & 78 & 4517.91 & 172.65 & 2123 & 144 & 12891.99 & 111.70 & $1.55(1.17 \text { to } 2.04)^{\$}$ & 1.00 (ref.) & 1.00 (ref.) \\
\hline Yes & 557 & 59 & 2699.50 & 218.56 & 425 & 33 & 1998.16 & 165.15 & 1.32 (0.86 to 2.03$)$ & $1.43(1.12 \text { to } 1.82)^{\$}$ & $1.16(0.88$ to 1.54$)$ \\
\hline \multicolumn{12}{|c|}{ Diabetes mellitus } \\
\hline No & 828 & 95 & 4995.69 & 190.16 & 2331 & 164 & 13814.23 & 118.72 & $1.60(1.24 \text { to } 2.06)^{\ddagger}$ & 1.00 (ref.) & 1.00 (ref.) \\
\hline Yes & 446 & 42 & 2221.72 & 189.04 & 217 & 13 & 1075.93 & 120.83 & $1.56(0.84$ to 2.91$)$ & 1.14 (0.85 to 1.52$)$ & $0.80(0.58$ to 1.10$)$ \\
\hline \multicolumn{12}{|c|}{ Cardiovascular disease } \\
\hline No & 1073 & 114 & 6119.97 & 186.28 & 2413 & 163 & 14189.06 & 114.88 & $1.62(1.28 \text { to } 2.06)^{\ddagger}$ & 1.00 (ref.) & 1.00 (ref.) \\
\hline Yes & 201 & 23 & 1097.44 & 209.58 & 135 & 14 & 701.10 & 199.69 & $1.05(0.54$ to 2.04$)$ & $1.47(1.05 \text { to } 2.08)^{\$}$ & $1.20(0.83$ to 1.75$)$ \\
\hline
\end{tabular}

$\neq p<0.001 ;{ }^{\$} p<0.05$.

${ }^{*}$ Estimated with Poisson regression.

†The model was adjusted by age, gender, hypertension, diabetes mellitus and cardiovascular disease.

ADs, anxiety disorders; IR, incidence rate, per 10000 person-years; IRR, incidence rate ratio; PY, person-year; ref., reference group; TBI, traumatic brain injury. 


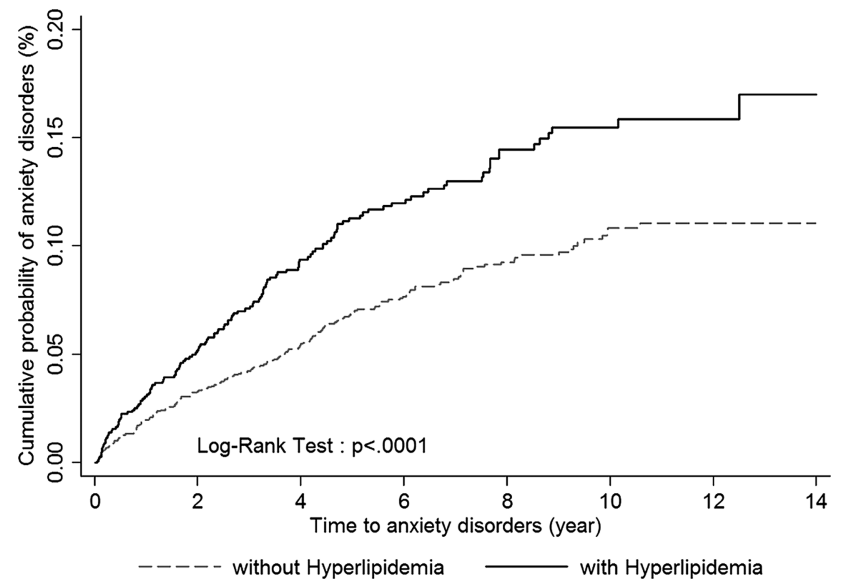

Figure 2 Kaplan-Meier plot for traumatic brain injury patients with anxiety disorders by hyperlipidaemia.

programme, the behaviours of health-seeking and cultural or social issues may affect the lower prevalence rate of ADs in patients with TBI, ${ }^{35}$ our finding indicated that the situation is changing, which could be from the improvement of health insurance programme or the change of health-seeking behaviours. Importantly, the prevalence of ADs in patients with TBI with preexisting hyperlipidaemia was always higher than that in patients without hyperlipidaemia. Therefore, the physicians including neurosurgeon, critical care physician, psychiatrists, physiatrists, caregivers can expect to see more patients with TBI who have pre-existing hyperlipidaemia in daily practice. At present, TBI is a major cause of death and neuropsychiatric disability in humans and remains a public health challenge. Whether the treatment of hyperlipidaemia prior to a TBI event helps improve post-traumatic new-onset ADs is worth exploring.

Furthermore, in a 3-year interventional study, the researchers found awareness of hyperlipidaemia had no effect on anxiety. ${ }^{36}$ In contrast, the other study indicated that simvastatin, an antihyperlipidaemia drug, caused significant anxiolytic effects in animals. ${ }^{26}$ In the current study, we did not investigate the impact of antihyperlipidaemia medications in pre-existing hyperlipidaemic patients before TBI, as the data were unavailable. However, in our study, we emphasise that physicians should pay more attention on the plasma hyperlipidaemia level of high-risk patients to prevent the occurrence of ADs after TBI in daily practice. Well-controlled hyperlipidaemia may attenuate the risk of developing ADs if a TBI has occurred.

In our study, we further elucidated and provided novel findings that pre-existing hyperlipidaemia is an independent risk factor for new-onset ADs after TBI, even when we controlled for DM, HTN and CAD. Therefore, hyperlipidaemia's neuropathological effects on the development of ADs after TBI should be investigated. Vogelzangs et al reported an elevation in the systemic inflammation biomarker $\mathrm{C}$ reactive protein in individuals with a late-onset $\mathrm{AD} .{ }^{37}$ Salim et al also demonstrated that anxiety is associated with neuroinflammation. ${ }^{38}$ Esmaillzadeh et al showed a positive association between hyperlipidaemia and markers of systemic inflammation and endothelial dysfunction. ${ }^{39}$ Furthermore, inflammatory actions of the neuroimmune system may contribute to the development of ADs following TBI. ${ }^{40}$ Taken together, we suppose that the inflammatory entity of

Table 3 Incidence of anxiety disorders in traumatic brain injury patients stratified by age group

\begin{tabular}{|c|c|c|c|c|c|c|c|c|c|c|}
\hline & \multicolumn{4}{|c|}{ TBI with hyperlipidaemia } & \multicolumn{4}{|c|}{ TBI without hyperlipidaemia } & \multirow[b]{2}{*}{ IRR $^{\star}(95 \% \mathrm{CI})$} & \multirow[b]{2}{*}{ Adjusted† HR (95\% Cl) } \\
\hline & $\overline{\mathbf{N}}$ & ADs & PY & Rate & $\overline{\mathbf{N}}$ & ADs & $\mathbf{P Y}^{\#}$ & Rate & & \\
\hline \multicolumn{11}{|l|}{ Age $<35$} \\
\hline Total & 82 & 7 & 651.46 & 107.45 & 164 & 8 & 1335.06 & 59.92 & $1.79(0.65$ to 4.94$)$ & 2.63 (0.58 to 4.71$)$ \\
\hline Male & 72 & 7 & 591.77 & 118.29 & 144 & 8 & 1217.52 & 65.71 & $1.80(0.65$ to 4.96$)$ & 1.00 (ref.) \\
\hline Female & 10 & 0 & 59.69 & 0.00 & 20 & 0 & 117.53 & 0.00 & $\mathrm{~N} / \mathrm{A}<$ always $\mathrm{NA}>$ & $\mathrm{N} / \mathrm{A}$ \\
\hline \multicolumn{11}{|c|}{ Age: $35-50$} \\
\hline Total & 274 & 29 & 1779.58 & 162.96 & 548 & 36 & 3657.26 & 98.43 & $1.66(1.02 \text { to } 2.70)^{\$}$ & $1.42(0.82$ to 2.47$)$ \\
\hline Male & 208 & 16 & 1359.21 & 117.72 & 417 & 18 & 2751.44 & 65.42 & 1.80 (0.92 to 3.53$)$ & 1.00 (ref.) \\
\hline Female & 66 & 13 & 420.36 & 309.26 & 131 & 18 & 905.82 & 198.72 & 1.56 (0.76 to 3.18$)$ & $2.81(1.73 \text { to } 4.58)^{\ddagger}$ \\
\hline \multicolumn{11}{|c|}{ Age: $50-65$} \\
\hline Total & 399 & 53 & 2128.21 & 249.04 & 797 & 53 & 4471.10 & 118.54 & $2.10(1.44 \text { to } 3.07)^{\ddagger}$ & $2.54(1.68 \text { to } 3.83)^{\ddagger}$ \\
\hline Male & 249 & 20 & 1344.10 & 148.80 & 495 & 23 & 2752.23 & 83.57 & 1.78 (0.98 to 3.24$)$ & 1.00 (ref.) \\
\hline Female & 150 & 33 & 7847.11 & 420.86 & 302 & 30 & 1718.87 & 174.53 & $2.41(1.47 \text { to } 3.95)^{\ddagger}$ & $2.44(1.65 \text { to } 3.60)^{\ddagger}$ \\
\hline \multicolumn{11}{|l|}{ Age: $>65$} \\
\hline Total & 519 & 48 & 2658.16 & 180.58 & 1039 & 80 & 5426.74 & 147.42 & $1.22(0.86$ to 1.75$)$ & $1.13(0.77$ to 1.67$)$ \\
\hline Male & 331 & 27 & 1630.31 & 165.61 & 664 & 44 & 3276.11 & 134.31 & $1.23(0.76$ to 1.99$)$ & 1.00 (ref.) \\
\hline Female & 188 & 21 & 1027.85 & 204.31 & 375 & 36 & 2150.63 & 167.39 & $1.22(0.71$ to 2.09$)$ & $1.30(0.92$ to 1.85$)$ \\
\hline
\end{tabular}




\begin{tabular}{|c|c|c|c|c|c|c|}
\hline $\begin{array}{l}\text { Adjusted* HR } \\
(95 \% \mathrm{Cl})\end{array}$ & Overall & $\leq 35$ only & $35-50$ only & 50-65 only & $>65$ only & Female only \\
\hline \multicolumn{7}{|l|}{ Age Group } \\
\hline$\leq 35$ & 1.00 (ref.) & & & & & - \\
\hline $35-50$ & 1.27 (0.55 to 2.92$)$ & & & & & 1.65 (0.80 to 3.41$)$ \\
\hline $50-65$ & $1.62(0.72$ to 3.66$)$ & & & & & $2.04(1.17 \text { to } 3.57)^{\$}$ \\
\hline$>65$ & 1.12 (0.49 to 2.59$)$ & & & & & 1.00 (ref.) \\
\hline \multicolumn{7}{|l|}{ Gender } \\
\hline Male & 1.00 (ref.) & 1.00 (ref.) & 1.00 (ref.) & 1.00 (ref.) & 1.00 (ref.) & \\
\hline Female & $1.97(1.40 \text { to } 2.77)^{\$}$ & to & $2.53(1.21 \text { to } 5.27)^{\$}$ & $2.97(1.70 \text { to } 5.21)^{\$}$ & $1.27(0.72$ to 2.26$)$ & \\
\hline \multicolumn{7}{|l|}{ Hypertension } \\
\hline No & 1.00 (ref.) & 1.00 (ref.) & 1.00 (ref.) & 1.00 (ref.) & 1.00 (ref.) & 1.00 (ref.) \\
\hline Yes & $1.14(0.78$ to 1.68$)$ & $11.73(1.37 \text { to } 100.58)^{\$}$ & $2.45(1.08 \text { to } 5.55)^{\$}$ & $0.61(0.32$ to to 1.14$)$ & 1.39 (0.75 to 2.60$)$ & $1.17(0.69$ to 1.98$)$ \\
\hline \multicolumn{7}{|c|}{ Diabetes mellitus } \\
\hline No & 1.00 (ref.) & 1.00 (ref.) & 1.00 (ref.) & 1.00 (ref.) & 1.00 (ref.) & 1.00 (ref.) \\
\hline Yes & 0.81 (0.55 to 1.19$)$ & to & 1.06 (0.47 to 2.42$)$ & $0.59(0.30$ to 1.14$)$ & 0.97 (0.54 to 1.76$)$ & $0.86(0.50$ to 1.47$)$ \\
\hline \multicolumn{7}{|c|}{ Cardiovascular disease } \\
\hline No & 1.00 (ref.) & 1.00 (ref.) & 1.00 (ref.) & 1.00 (ref.) & 1.00 (ref.) & 1.00 (ref.) \\
\hline Yes & $1.18(0.73$ to 1.90$)$ & to & $1.51(0.44$ to 5.21$)$ & 1.86 (0.80 to 4.37$)$ & $0.96(0.50$ to 1.85$)$ & $1.05(0.50$ to 2.22$)$ \\
\hline
\end{tabular}


hyperlipidaemia could aggravate new-onset ADs developed after TBI. Despite our results, there remains insufficient evidence to conclude what the role of the neuropathological consequences of pre-existing hyperlipidaemia may play in the development of new-onset ADs after TBI. However, we propose post-injury antiinflammation therapy may be a clinically useful strategy to prevent new-onset ADs in humans. This hypothesis should be investigated in the future.

Our study found that hyperlipidaemic women, specifically aged between 35 and 65 years, had an increased risk of new-onset ADs after TBI compared to men. In a 2-year national general population survey of comorbidity, the researchers found that the lifetime prevalence rates for $\mathrm{ADs}$ were $30.5 \%$ for women and $19.2 \%$ for men; women were more likely to develop ADs in their lifetime compared with men. ${ }^{41}$ The other studies reported the male to female prevalence ratios of ADs for 12 months and lifetime were $1: 1.79$ and $1: 1.7$, respectively. ${ }^{42}$ The possible explanations as to the greater susceptibility of women to ADs may be multifactorial. For example, genetic or environmental factors, ${ }^{43}$ the difference of absorption and distribution after specific antianxiety drug administration (psycho pharmacokinetic) during the treatment of women with $\mathrm{ADs},{ }^{44}$ and female reproductive hormones, such as oestrogen, may play a protective role in the development of ADs in women. ${ }^{18} 45$ Thus, our results are consistent with previous reports which showed that TBI female patients with hyperlipidaemia had a significantly higher risk for ADs than males. Using a subgroup analysis, we further found that TBI females with hyperlipidaemia aged $35-50$ years and $50-65$ years have a significantly increased risk of new-onset ADs (HR: 2.53 and 2.97, respectively) than males. Further, when only females were considered, we found hyperlipidaemic females aged 50-65 years have a significantly increased risk of new-onset ADs after TBI (HR: 2.04) than older females (age $>65$ ). Natural menopause usually occurs at a mean age of 51 years, and the suddenly reduced hormone resulting from the exhaustion of ovarian follicles may affect anxiety. ${ }^{46}$ However, as oestrogen levels were unavailable in our study, there was no sufficient evidence to conclude whether oestrogen has anti-anxiety effects on the development of new-onset ADs after patients with TBI with pre-existing hyperlipidaemia. Therefore, we consider the role of oestrogen and the interaction between oestrogen and hyperlipidaemia in ADs development after TBI as a critical issue to evaluate in the future.

There are several limitations to our study. First, the diagnoses, including ADs and other comorbidities, all relied on the claims data and ICD-9-CM diagnosis codes; thus, some disease misclassifications may exist. Second, we did not evaluate socioeconomic status, which may influence the development of ADs after TBI. Third, information regarding the severity of hyperlipidaemia was unavailable, which may also intervene the occurrence of ADs. Finally, some potential risk factors of TBI, such as the severity level and types, were not in the database. However, these potential risk factors may lead to different psychological effects. Therefore, in the future research, validating our findings with these potential risk factors is necessary.

\section{CONCLUSIONS}

Pre-existing hyperlipidaemia is an independent predictor for new-onset ADs after TBI. Hyperlipidaemic women, specifically aged between 35 and 65 years, had a significantly higher risk of new-onset ADs compared with men after TBI. Therefore, it is suggested that physicians should pay more attention to the plasma hyperlipidaemia level of high-risk patients to prevent the development of ADs after TBI.

\section{Author affiliations}

${ }^{1}$ Department of Medical Research, Chi-Mei Medical Center, Tainan, Taiwan

${ }^{2}$ Department of Hospital and Health Care Administration, Chia Nan University of Pharmacy and Science, Tainan, Taiwan

${ }^{3}$ Department of Psychiatry, Chi-Mei Medical Center, Tainan, Taiwan

${ }^{4}$ Department of Biotechnology, Southern Taiwan University of Science and Technology, Tainan, Taiwan

${ }^{5}$ Institute of Public Health, College of Medicine, National Cheng Kung University, Tainan, Taiwan

${ }^{6}$ Department of Psychiatry, National Cheng-Kung University, Tainan, Taiwan ${ }^{7}$ Department of Neurosurgery, Chi-Mei Medical Center, Tainan, Taiwan

Acknowledgements This study is based in part on data from the National Health Insurance Research Database provided by the National Health Insurance Administration, Ministry of Health and Welfare and managed by National Health Research Institutes. The interpretation and conclusions contained do not represent those of National Health Insurance Administration, Ministry of Health and Welfare or National Health Research Institutes.

Contributors $\mathrm{C}-\mathrm{HH}, \mathrm{J}-\mathrm{RK}$ and $\mathrm{K}-\mathrm{YH}$ conceived and designed the experiments. $\mathrm{C}-\mathrm{HH}, \mathrm{K}-\mathrm{YH}, \mathrm{J}-\mathrm{RK}$ and C-JL performed the experiments. C-HH, F-WL and J-RK analysed the data. J-JW, C-CC and C-HC contributed reagents/materials/ analysis tools. C-HH, J-RK, F-WL and K-YH wrote the paper.

Funding This research received no specific grant from any funding agency in the public, commercial or not-for-profit sectors.

\section{Competing interests None.}

Ethics approval Institutional Review Board (IRB), Chi-Mei Medical Center Tainan approved these study for exemption.

Provenance and peer review Not commissioned; externally peer reviewed.

Data sharing statement No additional data are available.

Open Access This is an Open Access article distributed in accordance with the Creative Commons Attribution Non Commercial (CC BY-NC 4.0) license, which permits others to distribute, remix, adapt, build upon this work noncommercially, and license their derivative works on different terms, provided the original work is properly cited and the use is non-commercial. See: http:// creativecommons.org/licenses/by-nc/4.0/

\section{REFERENCES}

1. Murray CJ, Lopez AD, Kovacs L, et al. Global health statistics: a compendium of incidence prevalence and mortality estimates for over 200 conditions. Gerontologist 1996;36:773-82.

2. Faul M, Xu L, Wald MM, et al. Traumatic brain injury in the United States: emergency department visits, hospitalizations, and deaths. Atlanta, GA: Centers for Disease Control and Prevention, National Center for Injury Prevention and Control, 2010;2:1-9.

3. Maas Al, Stocchetti N, Bullock R. Moderate and severe traumatic brain injury in adults. Lancet Neurol 2008;7:728-41. 
4. Gururaj G, Sastry Koeluri V, Chandramouli B, et al. Neurotrauma registry in the NIMHANS. Bangalore, India: National Institute of Mental Health \& Neurosciences, 2004.

5. Chiu WT, Yeh K, Li Y-C, et al. Traumatic brain injury registry in Taiwan. Neurol Res 1997;19:261.

6. Consensus Conference. Rehabilitation of persons with traumatic brain injury. NIH consensus development panel on rehabilitation of persons with traumatic brain injury. JAMA 1999;282:974-83.

7. Zaloshnja E, Miller T, Langlois JA, et al. Prevalence of long-term disability from traumatic brain injury in the civilian population of the United States, 2005. J Head Trauma Rehabil 2008;23:394-400.

8. Fann JR, Burington B, Leonetti A, et al. Psychiatric illness following traumatic brain injury in an adult health maintenance organization population. Arch Gen Psychiatry 2004;61:53.

9. Whelan-Goodinson R, Ponsford J, Johnston L, et al. Psychiatric disorders following traumatic brain injury: their nature and frequency. J Head Trauma Rehabil 2009;24:324-32.

10. Bryant RA, O'donnell ML, Creamer M, et al. The psychiatric sequelae of traumatic injury. Am J Psychiatry 2010;167:312-20.

11. Rockhill CM, Jaffe $\mathrm{K}$, Zhou C, et al. Health care costs associated with traumatic brain injury and psychiatric illness in adults. $J$ Neurotrauma 2012;29:1038-46.

12. Rosen JB, Schulkin J. From normal fear to pathological anxiety. Psychol Rev 1998;105:325.

13. Klonoff $\mathrm{H}$. Factor analysis of a neuropsychological battery for children aged 9 to 15. Percept Mot Skills 1971;32:603-16.

14. Moore EL, Terryberry-Spohr L, Hope DA. Mild traumatic brain injury and anxiety sequelae: a review of the literature. Brain Inj 2006;20:117-32.

15. Rogers JM, Read CA. Psychiatric comorbidity following traumatic brain injury. Brain Inj 2007;21:1321-33.

16. Byers AL, Yaffe K, Covinsky KE, et al. High occurrence of mood and anxiety disorders among older adults: the national comorbidity survey replication. Arch Gen Psychiatry 2010;67:489.

17. Bromberger JT, Kravitz HM, Chang Y, et al. Does risk for anxiety increase during the menopausal transition? Study of women's health across the nation. Menopause 2013;20:488-95.

18. Olafiranye $\mathrm{O}$, Jean-Louis $\mathrm{G}$, Zizi F, et al. Anxiety and cardiovascular risk: review of epidemiological and clinical evidence. Mind Brain: J Psychiatry 2011;2:32.

19. Tully PJ, Cosh SM, Baune BT. A review of the affects of worry and generalized anxiety disorder upon cardiovascular health and coronary heart disease. Psychol Health Med 2013;18:1-18.

20. Huang $\mathrm{C}-\mathrm{J}$, Chiu $\mathrm{H}-\mathrm{C}$, Lee $\mathrm{M}-\mathrm{H}$, et al. Prevalence and incidence of anxiety disorders in diabetic patients: a national population-based cohort study. Gen Hosp Psychiatry 2011;33:8-15.

21. Schmieder RE, Grassi G, Kjeldsen SE. Patients with treatment-resistant hypertension report increased stress and anxiety: a worldwide study. J Hypertens 2013;31:610-15.

22. Smith KJ, Béland M, Clyde M, et al. Association of diabetes with anxiety: a systematic review and meta-analysis. J Psychosom Res 2013;74:89-99.

23. van Reedt Dortland AK, Giltay EJ, et al. Metabolic syndrome abnormalities are associated with severity of anxiety and depression and with tricyclic antidepressant use. Acta Psychiatr Scand 2010;122:30-9.

24. van Reedt Dortland AK, Vreeburg SA, Giltay EJ, et al. The impact of stress systems and lifestyle on dyslipidemia and obesity in anxiety and depression. Psychoneuroendocrinology 2013;38:209-18.

25. Kawamoto R, Tabara Y, Kohara K, et al. Increased high-density lipoprotein cholesterol is associated with a high prevalence of pre-hypertension and hypertension in community-dwelling persons. Endocrine 2012;42:321-8.
26. Can ÖD, Ulupinar E, Özkay ÜD, et al. The effect of simvastatin treatment on behavioral parameters, cognitive performance, and hippocampal morphology in rats fed a standard or a high-fat diet. Behav Pharmacol 2012;23:582-92.

27. Chien I, Lin C-H, Chou Y-J, et al. Increased risk of hyperlipidemia in patients with major depressive disorder: a population-based study. J Psychosom Res 2013;75:270-4.

28. Cheng T-M. Taiwan's new national health insurance program: Genesis and experience so far. Health Aff 2003;22:61-76.

29. Cheng T-M. Taiwan's national health insurance system: high value for the dollar. Six Countries, Six Reform Models: their Healthcare Reform: Experience of Israel, the Netherlands, New Zealand, Singapore, Switzerland and Taiwan. Hackensack, NJ: World Scientific, 2009:171-204.

30. Havel RJ, Rapaport E. Management of primary hyperlipidemia. N Engl J Med 1995;332:1491-8

31. Chung SD, Lin HC. Association between chronic prostatitis/chronic pelvic pain syndrome and anxiety disorder: a population-based study. PLOS ONE 2013;8:e64630.

32. Chen $\mathrm{Y}-\mathrm{C}, \mathrm{Yeh} \mathrm{H}-\mathrm{Y}, \mathrm{Wu} \mathrm{J}-\mathrm{C}$, et al. Taiwan's National Health Insurance Research Database: administrative health care database as study object in bibliometrics. Scientometrics 2011;86:365-80.

33. Chang $\mathrm{H}-\mathrm{Y}$, Yeh $\mathrm{W}-\mathrm{T}$, Chang $\mathrm{Y}-\mathrm{H}$, et al. Prevalence of dyslipidemia and mean blood lipid values in Taiwan: results from the nutrition and health survey in Taiwan (NAHSIT, 1993-1996). Chin J Physiol 2002;45:187-98.

34. Hiott DW, Labbate L. Anxiety disorders associated with traumatic brain injuries. NeuroRehabilitation 2002:17:345-55.

35. Chien I-C, Chou Y-J, Lin C-H, et al. Prevalence of psychiatric disorders among national health insurance enrollees in Taiwan Psychiatr Serv 2004;55:691-7.

36. Einvik G, Ekeberg O, Lavik JG, et al. The influence of long-term awareness of hyperlipidemia and of 3years of dietary counseling on depression, anxiety, and quality of life. J Psychosom Res 2010;68:567-72.

37. Vogelzangs $\mathrm{N}$, Beekman $\mathrm{A}$, de Jonge $\mathrm{P}$, et al. Anxiety disorders and inflammation in a large adult cohort. Transl Psychiatry 2013;3:e249.

38. Salim S, Chugh G, Asghar M. Inflammation in anxiety. Adv Protein Chem Struct Biol 2012;88:1-25.

39. Esmaillzadeh A, Azadbakht L. Increased levels of inflammation among women with enlarged waist and elevated triglyceride concentrations. Ann Nutr Metab 2010;57:77-84.

40. Hoge E, Brandstetter K, Moshier S, et al. Broad spectrum of cytokine abnormalities in panic disorder and posttraumatic stress disorder. Depress Anxiety 2009;26:447-55.

41. Kessler RC, McGonagle KA, Zhao S, et al. Lifetime and 12-month prevalence of DSM-III-R psychiatric disorders in the United States: results from the national comorbidity survey. Arch Gen Psychiatry 1994;51:8.

42. McLean CP, Asnaani A, Litz BT, et al. Gender differences in anxiety disorders: prevalence, course of illness, comorbidity and burden of illness. J Psychiatr Res 2011;45:1027-35.

43. Kendler KS, Neale MC, Kessler RC, et al. Generalized anxiety disorder in women: a population-based twin study. Arch Gen Psychiatry 1992;49:267.

44. Jensvold MF, Halbreich UE, Hamilton JA. Psychopharmacology and women: sex, gender, and hormones. American Psychiatric Association, 1996.

45. Shear MK. Anxiety disorders in women: Gender-related modulation of neurobiology and behavior. Semin Reprod Endocrinol 1997;15:69.

46. Dratva J, Real FG, Schindler C, et al. Is age at menopause increasing across Europe? Results on age at menopause and determinants from two population-based studies. Menopause 2009;16:385-94. 